\title{
Revisiting Curcumin Chemistry- Part II: Synthesis of Monomethylcurcumin and Isomeric Demethoxycurcumins and their Characterization
}

\author{
E. VENKATA RAO*, Y. RAJENDRA PRASAD AND P. SUDHEER ${ }^{1}$ \\ College of Pharmaceutical Sciences, Andhra University, Visakhapatnam-530 003, ${ }^{1}$ Natco Research Centre, B-13 Industrial \\ estate, Sanathnagar, Hyderabad-500 018, India
}

Venkata Rao, et al.: Synthesis of Monomethylcurcumin and Demethoxycurcumins

\begin{abstract}
We have earlier reported the synthesis of the three major curcuminoids of turmeric employing a new strategy involving the use of borontrifluoride instead of boric oxide to protect the active methylene group of acetylacetone in reaction with aromatic aldehydes. We have now synthesized monomethyl products of curcumin and demethoxycurcumin by the same route and characterized them through their physical, chemical and spectral properties. As expected, a single monomethylcurcumin was obtained whereas we got two isomeric, monomethyl demethoxycurcumins when appropriate aromatic aldehydes were used in the condensation reaction. All the compounds were characterized through their difluoroboronites. The isomeric monomethyldemethoxycurcumins, reported for the first time, are distinctly different in melting point, thin layer chromatography and high performance liquid chromatography while their difluorobornites differed in ultra violet spectra. Dimethyl-bis-demethoxycurcumin and its difluoroboronite were prepared for the first time to confirm the involvement of 4/4'-hydroxyl in curcuminoids in quinonoid formation and consequent stability of their difluoroboronites. The monomethylcurcuminoids, especially those of demethoxycurcumin would be of interest for biological activity studies in comparison with curcumin.
\end{abstract}

Keywords: Monomethylcurcumin, isomeric monomethyl demethoxycurcumins, dimethyl-bisdemethoxycurcumin, difluoroboronites, synthesis, spectral data, HPLC

The major components of turmeric (Curcuma longa Linn.) are curcumin (1); demethoxycurcumin (2) and bis-demethoxycurcumin (3). Of these three, curcumin has been extensively studied and reported ${ }^{[1,2]}$ to possess a wide range of biological activities. In spite of extensive studies, no clinically useful product has yet emerged in modern medicine ${ }^{[3]}$ and it is used as a nutraceutical or a supplement in health foods. However studies are continuing to develop clinically useful agents, especially for the treatment of cancer ${ }^{[4]}$ and Alzhemier's ${ }^{[5]}$. From a scrutiny of some of the biological activity studies, it may be inferred that the unsaturated- $\beta$-diketone system and the phenolic $\mathrm{OH}$ group(s) in curcuminoids could be responsible for biological activity, while the role of methoxy groups is primarily confined to the hydrophilic/hydrophobic nature of the compounds resulting in enhancement or otherwise of a particular activity ${ }^{[6,7]}$. In order to evaluate the influence of methoxy groups, we felt a few more compounds in the curcuminoid group are necessary. Keeping this in view, monomethylcurcumin

*Address for correspondence E-mail: erraguntlavrao@yahoo.co.uk

September-October 2017
(4) and two monomethyldemethoxycurcumins (5 and 6 ) by the same route we developed ${ }^{[8]}$ involving the use of acetylacetonedifluoroboronite ${ }^{[9]}$ in the synthesis of curcuminoids $(1,2,3)$ for the first time. Compound (4) was also prepared from natural curcumin (1) by controlled methylation. The monomethylcurcuminoids have not so far been reported to occur in nature, but we had indication for the presence of compound (5) in the thin-layer chromatography (TLC) of turmeric extracts.

As already stated ${ }^{[8]}$, a majority of the processes for synthesis of curcuminoids followed Pabon's route ${ }^{[10]}$ with some variations involving the reaction of appropriate aromatic aldehydes with acetylacetone in the presence of boric oxide, tributylbutyrate and

This is an open access article distributed under the terms of the Creative Commons Attribution-NonCommercial-ShareAlike 3.0 License, which allows others to remix, tweak, and build upon the work non-commercially, as long as the author is credited and the new creations are licensed under the identical terms

Accepted 24 August 2017

Revised 05 March 2017

Received 30 November 2016

Indian J Pharm Sci 2017;79(5):820-828 
a base catalyst. A US patent ${ }^{[11]}$ reported a two stage synthesis of monomethylcurcumin (4) in $8.8 \%$ yield by the same process. Electrospray ionization mass spectrometry (ESI-MS) $\mathrm{M}^{+}$was quoted as also proton nuclear magnetic resonance ( ${ }^{1} \mathrm{H}$ NMR) data without any assignment. No other properties were mentioned. Synthesis of monomethyldemethoxycurcumins ( 5 and 6 ) is reported here for the first time.

In our previous paper ${ }^{[8]}$ we have stated that the presence of $p$-hydroxy group in the cinnamoyl moiety of curcuminoidsisaprerequisite forthequinonoidformation and consequent stability of the difluoroboronites. Pongamol $^{[12]}(7)$, a natural diaryl- $\beta$-diketone also forms a difluoroboronite ${ }^{[8]}$ (8) but is unstable to acid as it cannot assume a quinonoid form due to absence of an $\mathrm{OH}$ group. However, we felt that a more appropriate compound for comparison would be a curcuminoid without a phenolic $\mathrm{OH}$. Roughley and Whiting ${ }^{[13]}$ prepared and characterised dimethylcurcumin (9) and dimethyldemethoxycurcumin (10) but not dimethylbisdemethoxycurcumin (11). Literature search has not resulted in any information on this compound. So we prepared it from the natural product (3), as also its difluoroboronite (12) and characterized them to serve our purpose. Ultraviolet (UV) and infrared (IR) spectra of pongamoldifluoroboronite (8) have been reported ${ }^{[8]}$ but not the ${ }^{1} \mathrm{H}$ NMR and MS, which are now reported for comparison with the corresponding derivatives of curcuminoids.

\section{MATERIALS AND METHODS}

Acetylacetonedifluoroboronite ${ }^{[9]}$ and pongamoldi fluoroboronite ${ }^{[8]}(8)$ were prepared as per literature. $\mathrm{BF}_{3}$ used was borontrifluoride etherate $\left(\mathrm{BF}_{3} \cdot \mathrm{Et}_{2} \mathrm{O}\right)$. Water used was demineralised water. Bisdemethoxycurcumin (3) was isolated from commercial turmeric powder ${ }^{[8]}$. Aqueous methanol used for hydrolysis was $\mathrm{MeOH}-$ $\mathrm{H}_{2} \mathrm{O}(80: 20)$. Stirring during reactions was mechanical using magnetic stirrer or paddle stirrer depending on the volume of reaction mixture. TLC was carried out on silica gel pre-coated plates in solvent systems $\mathrm{CHCl}_{3}$ and $\mathrm{CHCl}_{3}-\mathrm{MeOH}$ (9.9:0.1) for curcuminoids and $\mathrm{CHCl}_{3}$ $\mathrm{MeOH}$ (9.8:0.2) for curcuminoiddifluoroboronites. Curcuminoids were detected by exposure to ordinary light and ammonia vapour. Compounds (7 and 8) were detected by exposure in iodine chamber. Column chromatography (CC) was carried out on silica gel (100200 mesh). High-performance liquid chromatography (HPLC) was carried out at room temperature (RT) on Novopak $(150 \times 3.9 \mathrm{~mm})$ column using $248 \mathrm{~nm}$ for detection. Mobile phase was a mixture of acetonitrile and phosphate buffer (0.05 M, pH 3, 500:500). TLC and HPLC results were presented in Table 1.

\section{General procedure for the synthesis of curcuminoids (4, 5 and 6):}

A mixture of two appropriate aldehydes $(10 \mathrm{mmol}$ each) was treated with ethyl acetate $(10 \mathrm{ml})$ and acetylacetonedifluoroboronite $(9.5 \mathrm{mmol})$ under stirring for $5 \mathrm{~min}$. $\mathrm{n}-\mathrm{BuNH}_{2}(0.287 \mathrm{ml})$ was added slowly with a $100 \mu 1$ micro syringe over 30 min under stirring and continued for $3 \mathrm{~h}$ after the addition. The solvent was distilled off from the reaction mixture and water $(40 \mathrm{ml})$ added followed by $1 \mathrm{~N} \mathrm{HCl}$ drop wise at $60^{\circ}$ under stirring until a $\mathrm{pH} 2-3$ was reached and then cooled. The product formed was collected by decantation. The residue was dissolved in $\mathrm{CHCl}_{3}$, washed with water, dried $\left(\mathrm{Na}_{2} \mathrm{SO}_{4}\right)$ and the solvent evaporated to get a solid.

\section{Synthesis of monomethylcurcumin (4) (fig. 1):}

Reaction of a mixture of vanillin (1.885 g, $12.5 \mathrm{mmol})$, veratraldehyde $(1.528 \mathrm{~g}, 12.5 \mathrm{mmol})$ and acetylacetonedifluoroboronite (1.694 g, 11.93 mmol) by the above procedure afforded a solid (5.48 g) which showed three spots in TLC corresponding to the difluoroboronites $(13,14,15)$ of compounds (1, 4 and 9), respectively. The mixture $(550 \mathrm{mg})$ was subjected to $\mathrm{CC}$ and eluted with $\mathrm{CHCl}_{3}$ followed by $\mathrm{CHCl}_{3}-\mathrm{MeOH}$ (9.9:0.1). The $\mathrm{CHCl}_{3}$ eluates gave a mixture $(148 \mathrm{mg})$ of all the three difluoroboronites in which (15) was the major component. The initial $\mathrm{CHCl}_{3}-\mathrm{MeOH}$ eluates gave a mixture $(182 \mathrm{mg})$ of (14, major) and (15, minor). The later eluates afforded a mixture $(62 \mathrm{mg})$ of (13 and 14).

The middle fraction consisting of compounds $(14,15 ; 150 \mathrm{mg})$ was dissolved in aq. $\mathrm{MeOH}(60 \mathrm{ml})$, $\mathrm{pH}$ adjusted to 6 and kept at $70^{\circ}$ under stirring for 3-4

\begin{tabular}{|c|c|c|c|}
\hline \multirow{2}{*}{$\begin{array}{l}\text { Compound } \\
\text { No. }\end{array}$} & \multicolumn{2}{|r|}{ TLC $R_{m}$} & \multirow{2}{*}{ HPLC $R_{t}$} \\
\hline & $\mathrm{CHCl}_{3}$ & $\mathrm{CHCl}_{3}-\mathrm{MeOH}(9.9: 0.1)$ & \\
\hline 1 & 3 & 3.5 & 3.431 \\
\hline 2 & 2 & 2.3 & 3.156 \\
\hline 3 & 1.5 & 1.8 & - \\
\hline 4 & 3.8 & 4.1 & 6.203 \\
\hline 5 & 4.5 & 4.8 & 10.156 \\
\hline 6 & 3.8 & 3.6 & 5.623 \\
\hline 11 & 5.3 & 5.1 & - \\
\hline
\end{tabular}




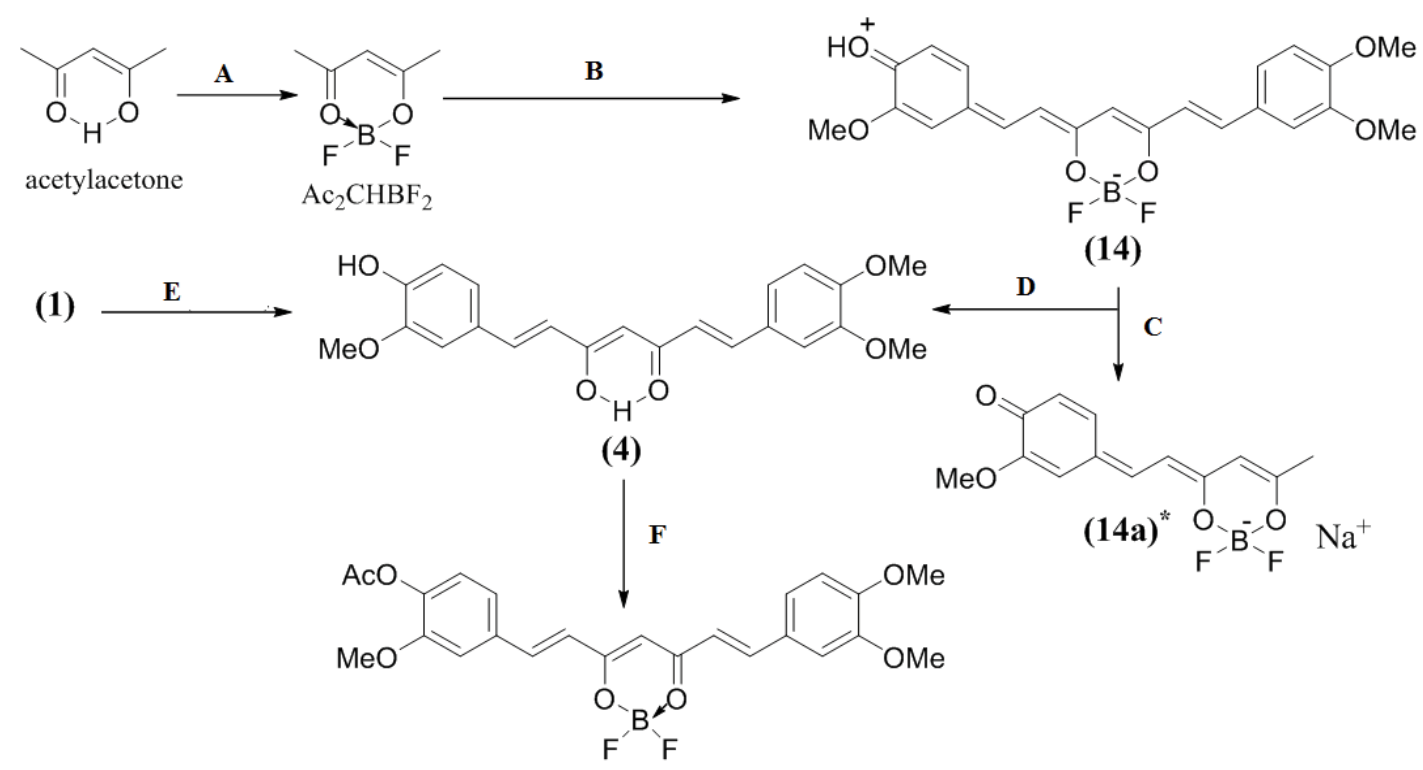

Fig. 1: Synthesis of monomethylcurcumin

(19)

*The alkali products 14a, 16a and 17a in figs. 1 and 2 were not isolated, but presumed to have quinone structure. A: $\mathrm{BF}_{3}$.Et $\mathrm{O}_{2}$; $\mathrm{CHCl}_{3}$. B: vanillin (1 mol); EtOAc, $\mathrm{n}-\mathrm{BuNH}_{2}$, veratraldehyde (1 mol). C: MeOH; NaOH. D: aq. MeOH, $70^{\circ}$, pH=6. E: DMSO (1.1 $\mathrm{mol}) ; \mathrm{CH}_{3} \mathrm{COCH}_{3}, \mathrm{~K}_{2} \mathrm{CO}_{3} . \mathrm{F}: \mathrm{BF}_{3} \cdot \mathrm{Et}_{2} \mathrm{O}, \mathrm{Ac}_{2} \mathrm{O}$

h. The solution was concentrated to $1 / 3$ volume and the aq. layer kept at $5^{\circ}$ over-night. The solid separated was dissolved in $\mathrm{CHCl}_{3}$ and extracted with $4 \%$ aq. $\mathrm{NaOH}$. The alkali layer was immediately neutralized with $6 \mathrm{~N} \mathrm{HCl}$ under stirring at $10^{\circ}$. The solid separated was filtered, washed with water and dried $(131 \mathrm{mg})$.

\section{Controlled methylation of (1) to get compound (4):}

Compound (1), $200 \mathrm{mg}$ was treated with acetone (8 ml), anhydrous $\mathrm{K}_{2} \mathrm{CO}_{3} \quad(200 \mathrm{mg})$ and dimethylsulphate $(1.8 \mu 1,1.1 \mathrm{~mol})$. The mixture was refluxed for $7 \mathrm{~h}$ and after cooling, filtered washed with acetone and the acetone solution concentrated to $1 / 3$ of its volume. It was then poured into cold water under stirring and left in a fridge over-night. It was extracted with $\mathrm{CHCl}_{3}(3 \times 8 \mathrm{ml})$, the $\mathrm{CHCl}_{3}$ layer washed with water, dried and evaporated to get a product $(236 \mathrm{mg}$ ) comprising of compounds $(4,9)$ and unreacted (1) in approx. 1:1:1 ratio (TLC). The mixture (14 $\mathrm{mg}$ ) was subjected to PTLC on silica gel HPTLC plates in $\mathrm{CHCl}_{3}-\mathrm{MeOH}$ (9.9:0.1). The middle spot corresponding to compound (4) was eluted to get $8.1 \mathrm{mg}$, which was identical with the synthetic sample.

\section{Synthesis of monomethyldemethoxycurcumin (5)} (fig. 2):

Following the general procedure described above, reaction of a mixture of vanillin (1.34 g, $8 \mathrm{mmol})$, anisaldehyde $(1.09 \mathrm{~g}, 8 \mathrm{mmol})$ and acetylacetonedifluoroboronite $\quad(0.984 \quad \mathrm{~g}, \quad 7.72$ mmol) afforded $2.56 \mathrm{~g}$ of solid consisting of the curcuminoiddifluoroboronites $(12,13)$ and (16; TLC). The mixture was hydrolysed with aq. $\mathrm{MeOH}$ (700 $\mathrm{ml})$ and worked up as described under compound (4) resulting in the formation of a product $(1.9 \mathrm{~g})$. TLC showed it to be a mixture of compounds (1, 5 and 11) with some impurities. The mixture $(1 \mathrm{~g})$ was subjected to $\mathrm{CC}$ using $\mathrm{CHCl}_{3}$ for elution collecting 15 fractions in all. Fractions (1-5) gave (11 and 5), fractions (6-9) gave mainly (5) with some (11) and the fractions (10-15) gave mainly (1) with some (5). Fractions (6-9) were combined and again subjected to $\mathrm{CC}$ using $\mathrm{CHCl}_{3}$ for elution. The initial fractions gave (11) and the later fractions gave pure compound $(5 ; 194 \mathrm{mg})$.

\section{Synthesis of isomonomethyldemethoxycurcumin (6) (fig. 2):}

Following the general procedure, reaction of a mixture of veratraldehyde (1.67 g, $10 \mathrm{mmol})$, p-hydroxybenzaldehyde $(2.3 \mathrm{~g}, 10 \mathrm{mmol})$ and acetylacetonedifluoroboronite $(1.2 \mathrm{~g}, 8.45 \mathrm{mmol})$ afforded a solid (3.4 g) which showed in TLC $\left(\mathrm{CHCl}_{3}\right.$ $\mathrm{MeOH}, 9.3: 0.7)$ curcuminoiddifluoroboronites $(15,17$ and 18). The product was hydrolysed with aq. $\mathrm{MeOH}$ $(700 \mathrm{ml})$ and worked up as described under compound (4) resulting in a solid mixture $(2.4 \mathrm{~g})$ consisting of compounds (3,6 and 9). The mixture ( $1 \mathrm{~g})$ was subjected to $\mathrm{CC}$ using $\mathrm{CHCl}_{3}$ (5 fractions) and $\mathrm{CHCl}_{3}$ - 
$\mathrm{MeOH}$ (9.9:0.1; 11 fractions) for elution. The $\mathrm{CHCl}_{3}$ eluates gave compound (9), $\mathrm{CHCl}_{3}-\mathrm{MeOH}$ fractions (6-9) a mixture of mainly compound (6) with some (9), fractions (10-12) a mixture of compounds (3 and 6) and the remaining fractions compound (3). Fractions (6-9) were combined and again subjected to CC using only $\mathrm{CHCl}_{3}$ for elution. The initial three fractions gave (9) and the later fractions afforded the pure compound (6; $196 \mathrm{mg}$ ).

\section{Preparation of dimethylbisdemethoxycurcumin (11) (fig. 3):}

Bisdemethoxycurcumin $(3 ; 25 \mathrm{mg})$ was treated with dry ether $(15 \mathrm{ml})$ in a stoppered flask and to the suspension diazomethane $(20 \mathrm{ml})$ was added slowly under stirring. The mixture was kept at $5-10^{\circ}$ for $6 \mathrm{~h}$ with occasional shaking. After evaporation of the solvent, the process was repeated three more times. The final product was taken in $\mathrm{CHCl}_{3}$-ether (1:9) and the dissolved portion was evaporated and the residue subjected to $\mathrm{CC}$ using $\mathrm{CHCl}_{3}$ for elution. The eluates free from compound (3; TLC) were combined and evaporated to give compound (11; $18 \mathrm{mg})$.

\section{General procedure for the preparation of curcuminoiddifluoroboronites for spectra:}

Compound (6 - $10 \mathrm{mg}$ ) in EtOAc or $\mathrm{CHCl}_{3}(1-2 \mathrm{ml})$ was treated with $\mathrm{BF}_{3} . \mathrm{Et}_{2} \mathrm{O}(0.1-0.2 \mathrm{ml})$ in a stoppered tube and kept at RT for about $2 \mathrm{~h}$ with occasional shaking. Red colour was usually observed on the addition of the reagent. The solvent was evaporated and aq. $\mathrm{MeOH}$ added drop wise. Red-brown gummy solid separated out on refrigeration. The supernatant layer (orange-yellow) was decanted and the residue treated with $\mathrm{MeOH}$ and evaporated, repeating the process a few more times to get a product in powder form and examined in TLC. Final purification of the products was done by passing an acetone solution through a small column of silica gel and eluting with the same solvent to get a product (7-11 mg). All the curcuminoiddifluoroboronites gave negative ferric reaction.

\section{Preparation of acetylmonomethylcurcumindifluoro boronite (19):}

Compound (4; $50 \mathrm{mg})$ was treated with ether $(2 \mathrm{ml})$ and $\mathrm{Ac}_{2} \mathrm{O}(1.2 \mathrm{ml})$. To the mixture $\mathrm{BF}_{3} . \mathrm{Et}_{2} \mathrm{O}(0.5 \mathrm{ml})$ was added drop wise, stoppered and left in a fridge overnight. It was poured into water and kept at RT for $2 \mathrm{~h}$. The separated solid was filtered, washed with cold $\mathrm{NaHCO}_{3}$ solution, followed by water and dried (54 mg). Compound (19) moved faster than (14) in TLC. Structures of curcuminoids and their difluoroboronites were shown in fig. 4.

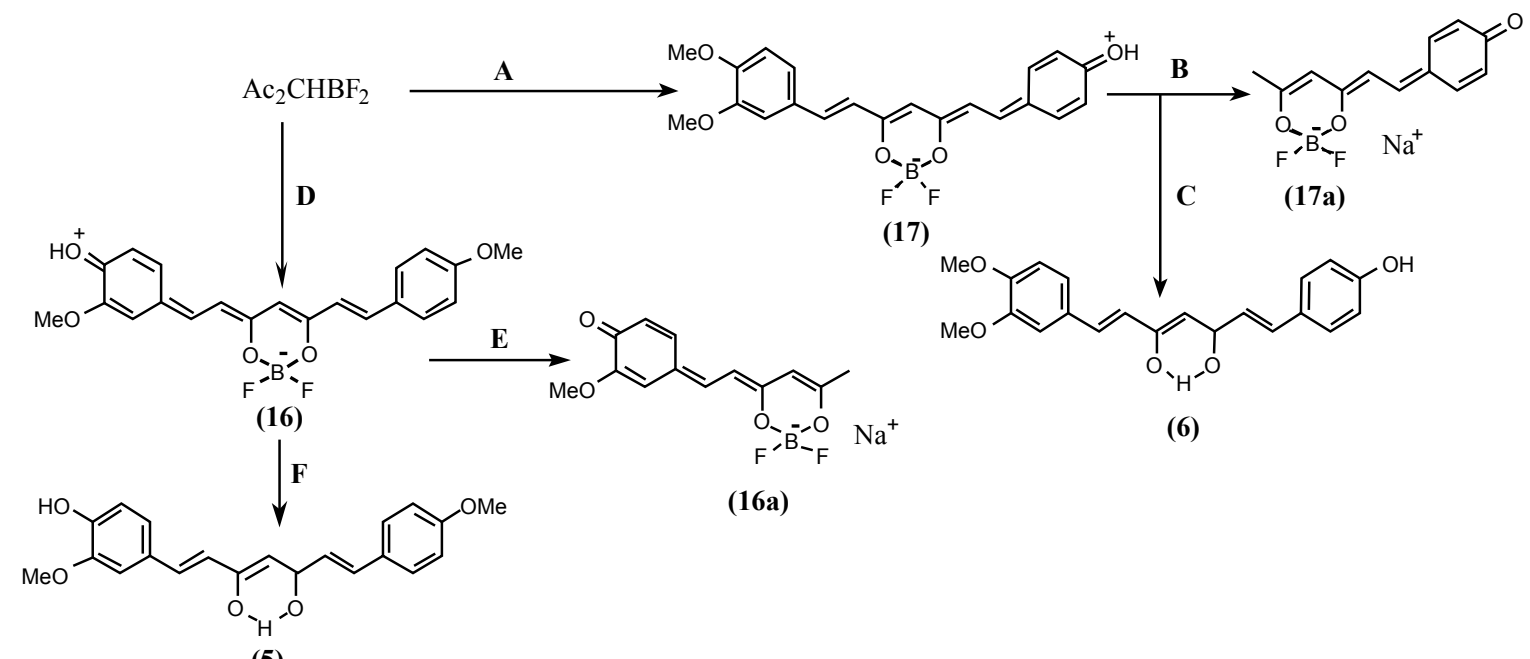

(5)

Fig. 2: Synthesis of monomethyldemethoxycurcumin and isomonomethyldemethoxycurcumin A: Veratraldehyde (1 mol), p-hydroxy benzaldehyde (1 mol); n-BuNH. EtOAc. B: MeOH, NaOH. C: aq. MeOH, pH=6. D: vanillin (1 mol), p-methoxy benzaldehyde (1 mol); n-BuNH2.EtOAc. E: MeOH, NaOH. F: aq. MeOH, pH=6

(3)

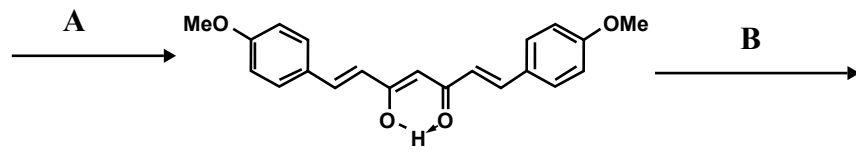

(11)<smiles>COc1ccc(/C=C2/C=C(/C=C/c3ccc(OC)cc3)O[P+](F)(F)O2)cc1</smiles>

(12)

Fig. 3: Preparation of dimethylbisdemethoxycurcumin and its difluoroboronite $\mathrm{A}: \mathrm{CH}_{2} \mathrm{~N}_{2}$ in ether. $\mathrm{B}$ : $\mathrm{BF}_{3} \mathrm{Et}_{2} \mathrm{O} ; \mathrm{CHCl}_{3}$ 


\section{Characterization of compounds:}

Monomethylcurcumin (4), MF. $\mathrm{C}_{22} \mathrm{H}_{22} \mathrm{O}_{6}$, yellowish brown microcrystalline powder from aq. $\mathrm{MeOH}$,
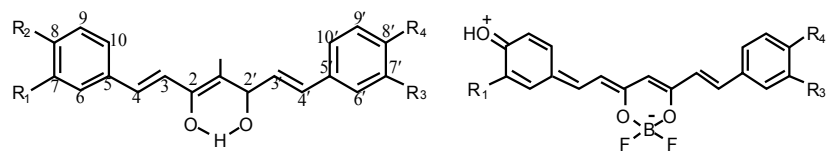

A<smiles>[R]c1ccc(C#C/C(=C/C(=O)/C=C/c2ccc([R])c([R])c2)O[B-](F)(F)F)cc1[R]</smiles>

$\mathrm{C}$

Fig. 4: Structures of curcuminoids and their difluoroboronites A: (1) $\mathrm{R} 1=\mathrm{R3}=\mathrm{OMe}$; $\mathrm{R2}=\mathrm{R} 4=\mathrm{OH}$; (2) $\mathrm{R3}=\mathrm{H}$; $\mathrm{R} 1=\mathrm{OMe}$ $\mathrm{R} 2=\mathrm{R} 4=\mathrm{OH} ; \quad$ (3) $\mathrm{R} 1=\mathrm{R3}=\mathrm{H} ; \quad \mathrm{R2}=\mathrm{R} 4=\mathrm{OH} ; \quad$ (9) $\mathrm{R} 1=\mathrm{R3}=$ $\mathrm{R} 2=\mathrm{R} 4=\mathrm{OMe} ; \quad$ (10) $\mathrm{R3}=\mathrm{H} ; \quad \mathrm{R} 1=\mathrm{R} 2=\mathrm{R} 4=\mathrm{OMe} . \quad \mathrm{B}: \quad$ (13) $\mathrm{R} 1=\mathrm{R3}=\mathrm{OMe} ; \mathrm{R} 4=\mathrm{OH} ;(\mathbf{1 8}) \mathrm{R} 1=\mathrm{R3}=\mathrm{H} ; \mathrm{R} 4=\mathrm{OH}$. $\mathrm{C}$ : (20) diacetyl curcumindifluoroboronite $(\mathrm{R} 2=\mathrm{R} 3=\mathrm{Ome} ; \mathrm{R2}=\mathrm{R} 4=\mathrm{OAc}) ;(15)$ dimethylcurcumindifluoroboronite $(\mathrm{R} 1=\mathrm{R} 2=\mathrm{R3}=\mathrm{R} 4=\mathrm{OMe})$ mp: $91-93^{\circ}$, yield $24.2 \%$, ferric colour-dark red, UV-IR (Table 2), ${ }^{1} \mathrm{H}$ NMR (Table 3), EIMS (40-600 Da) $\mathrm{m} / z$ (rel. int.), $382\left(\mathrm{M}^{+}, 9.46\right), 364$ $\left(\mathrm{M}^{+}-\mathrm{H}_{2} \mathrm{O}, 6.76\right), 208$ (8.11), 149 (8.11), 87 (9.46), 83 (100). Monomethylcurcumindifluoroboronite (14), $\mathrm{C}_{22} \mathrm{H}_{21} \mathrm{O}_{6} \mathrm{BF}_{2}$, red brown powder from acetoneether, mp: $181-84^{\circ}$, UV-IR (Table 2), ${ }^{1} \mathrm{H}$ NMR (Table 3), FABMS $m / z$ (rel. int.) $430\left(\mathrm{M}^{+}, 3.52\right), 411$ $\left(\mathrm{M}^{+}-\mathrm{F}^{\circ}, 15.5\right), 391 \quad\left(\mathrm{M}^{+}-\mathrm{HF}, 12.17\right), 307$ (33.79), 289 (19.71), 219 (9.15), 154 (100), 136 (43.36). Acetylmonomethylcurcumindifluoroboronite (19), light brown powder from $\mathrm{MeOH}$-ether, IR (Table 2). Monomethyldemethoxycurcumin (5), MF. $\mathrm{C}_{21} \mathrm{H}_{20} \mathrm{O}_{5}$, brownish yellow microcrystalline powder from aq. $\mathrm{MeOH}$, mp: $133-36^{\circ}$, yield $21.4 \%$, ferric colour-dark red, UV-IR (Table 2), ${ }^{1} \mathrm{H}$ NMR (Table 4), FABMS $\mathrm{m} / \mathrm{z}$ (rel. int.), $353\left(\mathrm{M}^{+}+1,100\right), 301$ (3.0), 273 (4.8), 259 (9.5), 257 (36.9), 236 (9.5), 235 (47.6), 219 (1.8), 202 (4.8). Monomethyldemethoxycurcumindifluoro boronite (16), red powder from acetone-ether, UV-IR

TABLE 2: UV AND IR DATA OF COMPOUNDS

\begin{tabular}{|c|c|c|c|c|c|}
\hline \multirow{3}{*}{$\begin{array}{l}\text { Compound } \\
\text { No. }{ }^{\circledR}\end{array}$} & \multicolumn{4}{|c|}{ UV } & \multirow{3}{*}{ IR flat $\mathbf{U}_{\max } \mathrm{cm}^{-1}$} \\
\hline & \multicolumn{2}{|l|}{$\mathrm{MeOH}$} & \multicolumn{2}{|c|}{ MeOH+alkali } & \\
\hline & Colour & $\lambda_{\max } \mathrm{nm}$ & Colour & $\lambda_{\max } \mathrm{nm}$ & \\
\hline 4 & Yellow & 418 & Orange & 455 & $3416,2925,2853,1626,1584,1024,950$ \\
\hline 14 & Light pink & 498 & Blue & 611 & $3401,1592,1538,1510,1059,1009$ \\
\hline 19 & - & - & - & - & $2926,1765,1618,1544,1266,1050,1014,809$ \\
\hline 5 & Yellow & 416 & Orange & 452 & $3406,1625,1595,1511,1259,1038,976,847$ \\
\hline 16 & Orange & 489 & Blue & 589 & $\begin{array}{c}3379,1594,1570,1532, \begin{array}{c}1489,1454,1426,1358,1269 \\
1156\end{array}\end{array}$ \\
\hline 6 & Yellow & 417 & Orange & 445 & $3517,2923,1626,1597,1452,1031,964$ \\
\hline 17 & Orange & 486 & Purple & 558 & $3224,1599,1539,1510,1289,1268,1063,1006$ \\
\hline 11 & Yellow-green fl. & 411 & Yellow & 413 & *2919, 1625, 1601, 1573, 1511, 1421, 976 \\
\hline 12 & Yellow & 446 & Deep yellow & 480 & $* * 2934,1600,1529,1425,977,830$ \\
\hline
\end{tabular}

${ }^{*} \mathrm{KBr}$ disc, ${ }^{* *} \mathrm{CHCl}_{3}$. ${ }^{\circledR}$ For data of other compounds mentioned in the text Ref ${ }^{[8]}$

TABLE 3: 'H NMR DATA OF COMPOUNDS (1), (13), (4) AND (14) 200 MHz PPM FROM TMS AS INTERNAL STANDARD, $J(\mathrm{~Hz})$

\begin{tabular}{lcccc}
\hline Protons & $(1)^{\mathrm{a}, \mathrm{c}}$ & $(13)^{\mathrm{b}, \mathrm{c}}$ & $(4)^{\mathrm{a}}$ & $(14)^{\mathrm{b}}$ \\
\hline $4,4^{\prime}$ & $7.59,2 \mathrm{H}, d(15.8)$ & $7.89,2 \mathrm{H}, d(15.6)$ & $7.64,2 \mathrm{H}, d d(2,16)$ & $7.92,2 \mathrm{H}, d(16.2)$ \\
6, 6' & $7.15,2 \mathrm{H}, d(2)$ & $7.41,2 \mathrm{H}, d(1.6)$ & $7.16,2 \mathrm{H}, d d(4,8)$ & $7.48,2 \mathrm{H}, d(1.8)$ \\
10, 10' & $7.08,2 \mathrm{H}, d d(1.8,9)$ & $7.30,2 \mathrm{H}, d d(2,8.6)$ & $7.0,2 \mathrm{H}, d d(2,8)$ & $7.44,2 \mathrm{H}, d d(2.8)$ \\
9, 9' & $6.93,2 \mathrm{H}, d(8.2)$ & $6.91,2 \mathrm{H}, d(8)$ & $6.92,2 \mathrm{H}, d(8)$ & $7.37,2 \mathrm{H}, d(8)$ \\
3, 3' & $6.48,2 \mathrm{H}, d(15.8)$ & $6.93,2 \mathrm{H}, d(14.6)$ & $6.52,2 \mathrm{H}, d d(2.8,16)$ & $7.06,2 \mathrm{H}, s(15.4)$ \\
1 & $5.81,1 \mathrm{H}, \mathrm{s}$ & $6.38,1 \mathrm{H}, \mathrm{s}$ & $5.85,1 \mathrm{H}, \mathrm{s}$ & $6.38,1 \mathrm{H}, \mathrm{s}$ \\
7, 7' OMe & $3.97,3.95,6 \mathrm{H}, s, s$ & $3.94,3.87,6 \mathrm{H}, \mathrm{s}, \mathrm{s}$ & - & - \\
7', 8' OMe & - & - & $3.98,3,97,6 \mathrm{H}, s, s$ & $3.91,6 \mathrm{H}, \mathrm{s}$ \\
7 OMe & - & - & $3.96,3 \mathrm{H}, \mathrm{s}$ & $3.94,3 \mathrm{H}, \mathrm{s}$ \\
\hline
\end{tabular}

${ }^{\mathrm{a}} \mathrm{CDCl}_{3},{ }^{\mathrm{b}}\left(\mathrm{CD}_{3}\right)_{2} \mathrm{CO}$, ${ }^{\mathrm{c}}$ data from Ref ${ }^{[8]}$ used for assignments in compounds 4 and 14. 
(Table 2). Isomonomethyldemethoxycurcumin (6), MF. $\mathrm{C}_{21} \mathrm{H}_{20} \mathrm{O}_{5}$, pale yellow microcrystalline powder from aq. $\mathrm{MeOH}, \mathrm{mp}: 158-60^{\circ}$, yield $26.6 \%$, ferric colour-red brown, UV-IR (Table 2), ${ }^{1} \mathrm{H}$ NMR (Table 4), FDMS $m / z$ (rel. int.), $353\left(\mathrm{M}^{+}+1,100\right), 317$ (4.2), 301 (12.5), 269 (7.1), 259 (21.4), 245 (8.9), 233 (3.0), 217 (4.8), 215 (9.5), 212 (5.4), 202 (11.3).

Isomonomethyldemethoxycurcumindifluoroboronite (17), red brown powder from acetone-ether, UV-IR (Table 2). Dimethylbisdemethoxycurcumin (11), orange red needles from $\mathrm{MeOH}$-ether, mp: $169-70^{\circ}$, yield $40.3 \%$, ferric colour-red brown, UV-IR (Table 2), ${ }^{1} \mathrm{H}$ NMR (Table 5).

Dimethylbisdemethoxycurcumindifluoroboronite (12), reddish brown powder from acetone-ether, UV and IR (Table 2), ${ }^{1} \mathrm{H}$ NMR (Table 5). Pongamol (7), MF.
$\mathrm{C}_{18} \mathrm{H}_{14} \mathrm{O}_{4},{ }^{1} \mathrm{H}$ NMR (Table 6), ES+ MS $m / z$ (rel. int.), 296 $\left([\mathrm{M}+\mathrm{H}]^{+}+1,10.6\right), 295\left([\mathrm{M}+\mathrm{H}]^{+}, 49.7\right), 197$ (5.6), 177 (100), 176 (22.5). Pongamoldifluoroboronite (8), MF. $\mathrm{C}_{18} \mathrm{H}_{13} \mathrm{O}_{4} \mathrm{BF}_{2},{ }^{1} \mathrm{H}$ NMR (Table 6), $\mathrm{ES}+\mathrm{MS} m / z$ (rel. int.), $325\left([\mathrm{M}+\mathrm{H}]^{+}+1-\mathrm{F}^{\circ}, 5.6\right), 324\left(\mathrm{M}^{+}+1-\mathrm{F}^{\circ}, 22.7\right), 323\left(\mathrm{M}^{+}-\right.$ $\left.\mathrm{F}^{\circ}, 100\right), 322\left(\mathrm{M}^{+}-1-\mathrm{F}^{\circ}, 26.9\right), 310$ (12.9), 309 (65.3), $277\left(\mathrm{M}^{+}+1-\mathrm{OBF}_{2}, 19.8\right), 263 \quad\left(\mathrm{C}_{18} \mathrm{H}_{12} \mathrm{O}_{3}, 12.6\right)$. Structures of pongamol and their derivatives were shown in fig. 5.

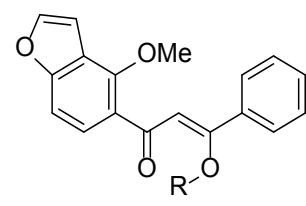

$$
\begin{aligned}
& \text { (7) } \mathrm{R}=\mathrm{H} \\
& \text { (7a) } \mathrm{R}=\mathrm{Me}
\end{aligned}
$$

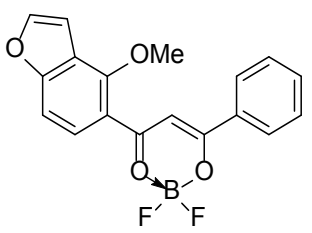

(8)
Fig. 5: Structures of pongamol and their derivatives

TABLE 4: ${ }^{1} \mathrm{H}$ NMR OF COMPOUNDS (2; $300 \mathrm{MHz}$ ), (5 AND 6; $200 \mathrm{MHz}$ ) PPM FROM TMS AS INTERNAL STANDARD, $J(\mathrm{~Hz})$

\begin{tabular}{lccc}
\hline Protons & \multicolumn{1}{c}{$2^{\mathrm{a}, \mathrm{b}}$} & $5^{\mathrm{a}}$ & $6^{\mathrm{a}}$ \\
\hline $4,4^{\prime}$ & $7.61,2 \mathrm{H}, d^{\prime} d^{\prime}(3,15.6)$ & $7.59,2 \mathrm{H}, d d(16.8)$ & $7.61,2 \mathrm{H}, d(15.6)$ \\
$6^{\prime}, 0^{\prime}$ & $7.47,2 \mathrm{H}, d(8.4)$ & $7.51,2 \mathrm{H}, d(8.8)$ & $7.46,2 \mathrm{H}, d(8.4)$ \\
6 & $7.37,1 \mathrm{H}, \mathrm{s}$ & $7.05,1 \mathrm{H}, \mathrm{s}$ & $7.08,1 \mathrm{H}, \mathrm{s}$ \\
10 & $7.12,1 \mathrm{H}, d(8)$ & $7.12,1 \mathrm{H}, d / d(1.8,8.4)$ & $7.14,1 \mathrm{H}, d(8.2)$ \\
$7^{\prime}, 9^{\prime}$ & $6.94,2 \mathrm{H}, d(8)$ & $6.92,2 \mathrm{H}, d(8)$ & $6.88,2 \mathrm{H}, d(8)$ \\
9 & $6.86,1 \mathrm{H}, d(8.4)$ & $6.91,1 \mathrm{H}, d(8.6)$ & $6.85,1 \mathrm{H}, d(8)$ \\
$3,3^{\prime}$ & $6.49,2 \mathrm{H}, d / d(2.4,15.9)$ & $6.48,2 \mathrm{H}, d / d(3.2,15.8)$ & $6.49,2 \mathrm{H}, d / d(2.1,15.6)$ \\
1 & $5.8,1 \mathrm{H}, \mathrm{s}$ & $5.79,1 \mathrm{H}, \mathrm{s}$ & $5.8,1 \mathrm{H}, \mathrm{s}$ \\
7 OMe & $3.98,3.396,3 \mathrm{H}, \mathrm{s}$ & $3.93,3 \mathrm{H}, \mathrm{s}$ & $3.93,3.92,6 \mathrm{H}, s$ \\
\hline
\end{tabular}

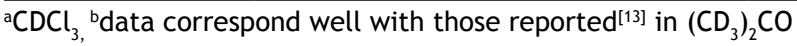

TABLE 5: ${ }^{1} \mathrm{H}$ NMR DATA OF COMPOUNDS OF (3; $\left.300 \mathrm{MHz}\right)$, (11 AND 12; $400 \mathrm{MHz}$ ) PPM FROM TMS AS INTERNAL STANDARD, $J(\mathrm{~Hz})$

\begin{tabular}{lccc}
\hline Protons & $3^{\mathrm{a}, \mathrm{b}}$ & $11^{\mathrm{c}}$ & $12^{\mathrm{a}}$ \\
\hline $4,4^{\prime}$ & $7.59,2 \mathrm{H}, d(16)$ & $7.62,2 \mathrm{H}, d(16)$ & $8,2 \mathrm{H}, d(16)$ \\
$6,6^{\prime}, 10,10$, & $7.51,4 \mathrm{H}, d(8)$ & $7.51,4 \mathrm{H}, d(8)$ & $7.58,4 \mathrm{H}, d(8)$ \\
$7,7^{\prime}, 9,9$, & $6.87,4 \mathrm{H}, d(8)$ & $6.92,4 \mathrm{H}, d(8)$ & $6.95,4 \mathrm{H}, d(8)$ \\
$3,3^{\prime}$ & $6.62,2 \mathrm{H}, d(14)$ & $6.650,2 \mathrm{H}, d(14)$ & $6.58,2 \mathrm{H}, d(14)$ \\
1 & $5.97,1 \mathrm{H}, \mathrm{s}$ & $5.79,1 \mathrm{H}, s$ & $6.01,1 \mathrm{H}, \mathrm{s}$ \\
$8,8^{\prime}$ OMe & - & $3.85,6 \mathrm{H}, s$ & $3.88,6 \mathrm{H}, s$ \\
\hline
\end{tabular}

${ }^{\mathrm{a}} \mathrm{CD}_{3} \mathrm{OD}$, b data correspond well with those reported ${ }^{[13]}$ in $\left(\mathrm{CD}_{3}\right)_{2} \mathrm{CO},{ }^{\mathrm{C}} \mathrm{CDCl}_{3}$

TABLE 6: ${ }^{1} \mathrm{H}$ NMR DATA OF COMPOUNDS (7 AND 8) IN $\mathrm{CDCl}_{3} 400 \mathrm{MHz}$ PPM FROM TMS AS INTERNAL STANDARD, $J(\mathrm{~Hz})$

\begin{tabular}{lcc}
\hline Protons & $7^{\mathrm{a}}$ & 8 \\
\hline $2 / 6$ & $7.96,2 \mathrm{H}, \mathrm{m}$ & $8.12,8.14, d / d 2 \mathrm{H}(1.2,1.2)$ \\
$5^{\prime}$ & $7.86,1 \mathrm{H}, d(9)$ & $8.18,1 \mathrm{H}, d(8.8)$ \\
$7^{\prime}$ & $7.64,1 \mathrm{H}, d(2)$ & $7.67,1 \mathrm{H}, d(2.4)$ \\
$3 / 4 / 5$ & $7.50,3 \mathrm{H}, m$ & $7.55,3 \mathrm{H}, m$ \\
$6^{\prime}$ & $7.32,1 \mathrm{H}, d(9)$ & $7.33,7.35,1 \mathrm{H}, d d(8.8)$ \\
8 & $7.16,1 \mathrm{H}, s$ & $7.74, \mathrm{H}, s$ \\
$8^{\prime}$ & $7.06,1 \mathrm{H}, d(2)$ & $7.06,1 \mathrm{H}, d(2)$ \\
Ar.OMe & $4.26,3 \mathrm{H}, s$ & $4.28,3 \mathrm{H}, s$ \\
\hline
\end{tabular}

${ }^{\text {a }}$ Data correspond well with those reported ${ }^{[12]}(100 \mathrm{MHz})$ 


\section{RESULTS AND DISCUSSION}

The three curcuminoids (4, 5 and 6), are all unsymmetrical molecules whose yields are always lower than symmetrical ones due to competing reactions of two different aldehydes. However, the yield of our synthetic monomethylcurcumin (4) is higher than that reported in the US patent ${ }^{[11]}$ for this compound. Controlled methylation of curcumin (1) to get (4) is an alternative which we have tried, but the yield is less than that of synthetic (4). Controlled methylation of demethoxycurcumin (2) to get (5 and 6) could have led to a complex mixture of products.

A scrutiny of TLC and HPLC results (Table 1) shows that monomethyldemethoxycurcumin (5) is the most hydrophobic among the group of curcuminoids that contain at least one phenolic $\mathrm{OH}$. The $\mathrm{R}_{\mathrm{t}} 10.156$ (HPLC) for (5) is baffling when its isomer (6) showed $R_{t} 5.63$. There is no possible explanation as of now. TLC results indicate the same trend, though the difference is not as wide. The $\mathrm{M}^{+}$observed for monomethylcurcumin (4) and its difluoroboronite (14) and $\mathrm{M}^{+}+1$ for the isomeric demethoxycurcumins (5 and 6) are consistent with their respective molecular formulae (MF). In the FABMS of (14) fragment ions with loss of $\mathrm{F}^{\circ}$ and $\mathrm{HF}$ from $\mathrm{M}^{+}$were observed which was not the case with curcumindifluoroboronite (13) $)^{[8]}$ in its EI $(20 \mathrm{ev})$ MS. The quasi-molecular ions $[\mathrm{M}+\mathrm{H}]^{++1}$ and $[\mathrm{M}+\mathrm{H}]^{+}$ observed for pongamol (7) in ES+ MS are consistent with its MF. $\mathrm{M}^{+}$in any form was not present in pongamoldifluoroboronite (8). The highest positive ion present is consistent with $[\mathrm{M}+\mathrm{H}]^{+}+1-\mathrm{F}^{\circ}$ and the most abundant ion at $\mathrm{m} / \mathrm{z} 323$ could be $\mathrm{M}^{+}-\mathrm{F}^{\circ}$. The $\mathrm{m} / \mathrm{z}$ at 277 (19.8) could be $\mathrm{M}^{+}+1-\mathrm{OBF}_{2}\left(\mathrm{C}_{18} \mathrm{H}_{12} \mathrm{O}_{3}\right)$ in analogy with the EIMS of $\beta$-methoxychalcone (O-methylpongamol) (7a) ${ }^{[12]}$ which arises from its $\mathrm{M}^{+}$by loss of $\mathrm{OCH}_{3}$.

Our observation ${ }^{[8]}$ that the presence of a free $p$-hydroxyl group in the cinnamoyl moieties of curcuminoids is necessary for the formation of difluoroboronites in quinonoid form and consequent stability is supported by the present work. In the IR spectra of curcuminoids, the chelated carbonyl appears in the range $1625-28 \mathrm{~cm}^{-1}$ (Table 2) and disappears in their difluoroboronites if a $p$-hydroxyl group is present in the parent compound. This is exemplified in the spectra of compounds (4, 5 and 6) having $p-\mathrm{OH}$ group and their difluoroboronites (15, 16 and 17). The chelated carbonyl will be present but gets shifted to $1600 \mathrm{~cm}^{-1}$ as in compound (12), as also in compound (19) due to lack of the $\mathrm{OH}$ group and consequent inability to form a quinonoid.

While the IR data reveals mainly the presence or absence of chelated carbonyl in curcuminoid difluoroboromites, UV data provide more useful information regarding the effect of $p$-hydroxyl group (Table 2). In compounds (4, 5 and 6$)$ having $p$-hydroxyl group, and their difluoroboronites (14, 16 and 17) bathochromic shift with colour change was observed on addition of alkali to $\mathrm{MeOH}$ solution. No such change was noticed in compounds $(7,8$ and 11). While all the curcuminoids with $p$-hydroxyl group formed difluoroboronites giving blue colour on addition of alkali to $\mathrm{MeOH}$ solution with $\lambda_{\max }$ in the range of 594-629 nm, only the difluoroboronite (17) of compound (6) gave purple colour with $\lambda_{\text {max }} 558 \mathrm{~nm}$, thus distinguishing it from its isomer (16) formed from (5). It was also observed that while pongamoldifluorobornite (8) got cleaved instantly on addition of alkali, dimethylbisdemethoxycurcumindifluoroboronite (12) gave a deep yellow colour on addition of alkali with a small shift in $\lambda_{\max }$. But it was only temporary. Either on long standing or on addition of drop of water it got cleaved and reverted to the parent compound (11). This could be due to the conjugate double bonds present in (11) and absent in (7).

The ${ }^{1} \mathrm{H}$ NMR data (Tables 3-6) also reflect the effect of the presence or absence of chelated carbonyl in 7 curcuminoids and four of their difluoroboronites which we have studied. The olefinic proton $(1-\mathrm{H})$ is central to curcuminoids and aryl- $\beta$-diketones in general. In six of the curcuminoids the chemical shift of 1-H appeared in the range of $\delta 5.79-5.85 \mathrm{ppm}$. Only in the case of compound (3) it was at $\delta 5.97$ ppm. This could be due to the absence of methoxyl groups because it appeared at $\delta 5.79 \mathrm{ppm}$ in its dimethyl derivatives (11). In the difluoroboronites (13 and 14) $1-\mathrm{H}$ got shifted to $\delta 6.38 \mathrm{ppm}$ (downfield shift of $0.57 \mathrm{ppm}$ in 13 and $0.53 \mathrm{ppm}$ in 14). The corresponding shift of $1-\mathrm{H}$ in the difluoroboronite (12) is only $0.22 \mathrm{ppm}$. Similarly the downfield shift of $1-\mathrm{H}$ in diacetylcurcumindifluoroboronite ${ }^{[8]}$ (20) is $0.30 \mathrm{ppm}$ ( $\delta 5.81$ to 6.11 ). As already stated the presence of $p$-hydroxyl in compounds (1 and 4) is responsible for their difluoroboronites (13 and 14) to exist in quinonoid form and the absence of the same in compound (11) led to its difluoroboronite (12) to have chelated carbonyl. Compound (20) was prepared from compound (1) having $p$-hydroxyl groups but in the 
process of its reaction with $\mathrm{BF}_{3} \cdot \mathrm{Et}_{2} \mathrm{O}$ in the presence of $\mathrm{Ac}_{2} \mathrm{O}$ acetylation of $p$-hydroxyl groups could have preceded the difluoroboronite formation.

In the natural diaryl- $\beta$-diketone ( $\beta$-hydroxychalcone) pongamol (7), the equivalent olefinic proton $(8-\mathrm{H})$ appeared at $\delta 7.16 \mathrm{ppm}$ (Table 6) much above the chemical shift of $1-\mathrm{H}$ of the curcuminoids as was the case with a similar $\beta$-hydroxychalcone, purpurenone ${ }^{[14]}$, isolated from the same plant Tephrosia purpurea. The down field shift of $8-\mathrm{H}$ in pongamoldifluoroboronite (8) is $0.58 \mathrm{ppm}$, although it does not exist in quinonoid form. These features may be attributed to the proximity of the aryl groups to the olefinic proton.

The ${ }^{1} \mathrm{H}$ NMR data of compounds (4 and 14) are comparable to that of (1 and 13) in that the downfield shift of all protons (other than $\mathrm{OMe}$ ) in the two pairs was observed with the exception of $9,9^{\prime}-\mathrm{H}$. The ${ }^{1} \mathrm{H}$ NMR spectra of the isomers (5 and 6) are very close except for chemical shift of the OMe protons which distinguishes the two isomers.

Of all the biological activities of curcumin (1), the more important are its anticancer ${ }^{[4]}$ and Alzheimer's ${ }^{[5]}$. Due to its poor water solubility, it could not attain much significance as an anticancer agent. Bisdemethoxycurcumin (3) is more water soluble, but it was not adequately investigated. Active principles of herbals serve as templates for synthetic drug optimization. Two such examples are the hybrid compounds with curcumin-thalidomide ${ }^{[15]}$ and curcumin-quinolone ${ }^{[16]}$ hybrids, which showed promising anticancer activity.

Since long, studies have revealed that curcumin (1) may fight Alzheimer's disease ${ }^{[5]}$. A recent study of Yang et al. ${ }^{[17]}$ has confirmed this view when they found that (1) inhibits the formation of amyloid- $\beta$-oligomers and fibrils. Their in vivo observation suggests that (1) may be beneficial even after the disease had developed. According to the authors, its hydrophobic nature might allow it to cross the blood brain barrier and bound plaques. In that case, monomethyldemethoxycurcumin (5) which is more hydrophobic than (1) can be expected to show this activity (unless two phenolic groups are essential) and a study of the same in comparison with (1) will be of interest.

In conclusion it may be stated that we successfully applied the new method we developed for the synthesis of known curcuminoids of turmeric to the synthesis of new unsymmetrical curcuminoids and characterized them by their chemical and spectral properties. The new compounds are of interest for biological testing and also for structure-activity related studies in curcuminoids and to assess the role of phenolic $\mathrm{OH}$ and methoxyl groups in the unsaturated $\beta$-diketone system which is supposed to be the backbone for all biological activities exhibited by curcumin.

\section{Acknowledgements:}

The authors (EVR and PS) thank Sri V. C. Nannapaneni, Chairman and Managing Director, Natco Pharma Ltd., Hyderabad for encouragement and his interest in this work. Their thanks are due to Dr. A. K. S. Bhujanga Rao, President, Natco Research Centre, Hyderabad for providing the HPLC data on curcuminoids. We thank Dr. G. S. Reddy, Research Scientist, OMM Scientific Inc., Dallas, Texas, USA and Prof. A. Raghurama Rao, College of Pharmaceutical Sciences, Kakatiya Univeristy, Warangal for NMR and Mass spectra. The authors (EVR and YRP) thank the research scholar Mr. Arun Satya Dev for help in experimental work carried out at the College of Pharmaceutical Sciences, Andhra University. Finally, we thank the Research Scholar, Mr. T. Vinay Bharadwaj, College of Pharmaceutical Sciences, Andhra University for excellent typing of the manuscript.

\section{Financial assistance:}

Nill.

\section{Conflicts of Interest:}

The authors declare no conflicts of interest.

\section{REFERENCES}

1. Chatopadhay I, Biswas K, Bandyopadhay I, Banerjee RK. Turmeric and curcumin: Biological activity and medical application. Curr Sci 2004;87:44-53.

2. Kulkarni SK, Dhir A. An overview of curcumin in neurological diseases. Indian J Pharm Sci 2010;72:149-54.

3. Rao EV. Turmeric and curcumin. Curr Sci 2004;87:132.

4. Chen YC, Kuo TC, Lin-Shiau SV, Lin JK. Induction of HSP70 gene expression by modulation of $\mathrm{Ca}+2$ ion and cellular P53 protein by curcumin in colorectal carcinoma cells. Mol Carcinog 1996;17:224-34.

5. Rover N. Untangling Alzheimer's. Chem Eng News 2005;83:38-45.

6. Masuda J, Jitoe A, Isobe J, Nakatani N, Yonomori S. Antioxidative and antiinflammatory curcumin related phenolics from rhizomes of Curcuma domestica. Phytochemistry 1993;32:1557-60.

7. Mazumdar A, Neamati N, Sunder S, Schutz J, Pertz H, Fich $\mathrm{E}$, et al. Curcumin analogs with altered potencies against HIV-I integrase as probes for biochemical mechanisms of drug action. J Med Chem 1997;40:3057-63. 
8. Rao EV, Sudheer P. Revisiting curcumin chemistry Part I: A new strategy for the synthesis of curcuminoids. Indian J Pharm Sci 2011;73:262-70.

9. Morgan GT, Turnbull RB. Boron $\beta$-diketonedifluorides. J Chem Soc 1924;125:1963-7.

10. Pabon HJ. A synthesis of curcumin and related compounds. Rec Trav Chim 1964;83;379-86.

11. Lee KH, Lin L, Shih C, Su CY, Ishida J, Ohtsu H, et al. Novel curcumin analogues and uses thereof. US Patent Number: US-200501872255A1.

12. Pelter A, Ward RS, Rao EV, Raju NR. 8-Substituted flavonoids and 7-substituted-7-oxygenated chalcones from Tephrosia purpurea. J Chem Soc Perkin I 1981;2491-8.
13. Roughley PJ, Whiting DA. Experiments in the biosynthesis of curcumin. J Chem Soc Perkin I 1973;2379-88.

14. Rao EV, Raju NR. Two flavonoids from Tephrosia purpurea. Phytochemistry 1984;23:2339-42.

15. Liu K, Zhang D, Choinacki J, Du Y, Eu H, Grant S, et al. Design and biological characterization of hybrid compounds of curcumin and thalidomide for multiple myeloma. Org Biomol Chem 2013;11:4757-63.

16. Raghavan S, Manogaran P, Narasimha KK, Kuppswami BK, Maryappan P, Gopalakrishnan A, et al. Synthesis and anticancer activity of novel curcumin-quinolone hybrids. Bioorg Med Chem Letts 2015;25;3601-05.

17. Yang F, Lim G, Begum A, Cebeda O, Simmons MR, Ambegaokar SS, et al. Curcumin inhibits formation of amyloid in vivo. J Biol Chem 2005;280:5892-901. 